Journal of

Cancer Research and Therapeutic Oncology

\title{
Wax Tissue Compensator for Head and Neck Radiotherapy - Fabrication and Dosimetric Evaluation
}

\author{
Challapalli Srinivas ${ }^{1{ }^{*}}$, Kamalaksh Shenoy ${ }^{1}$, Vidya $\mathrm{K}^{2}$, Ravichandran $\mathrm{R}^{3}$ \\ ${ }^{1}$ Department of Radiotherapy \& Oncology, Kasturba Medical College Hospital, Attavar, Mangalore, India \\ ${ }^{2}$ Department Prostodontics, Manipal College of Dental Sciences, Attavar, Mangalore, India \\ ${ }^{3}$ Department of Radiation Oncology, Royal Hospital, Sultanate of Oman, Muscat
}

${ }^{\star}$ Corresponding author: Challapalli Srinivas, Department of Radiotherapy \& Oncology, Kasturba Medical College

Hospital, Attavar, Mangalore, India; Email: challapallisnvas@yahoo.co.in; Tel: +91-9880414594

Received Date: May 13, 2015; Accepted Date: October 02, 2015; Published Date: October 06, 2015

Citation: Challapalli Srinivas, et al. (2015) Wax Tissue Compensator for Head and Neck Radiotherapy - Fabrication and Dosimetric Evaluation. J Cancer Res Therap Oncol 3: 1-5.

\begin{abstract}
Thickness and contour variations in head and neck regions introduce non-uniformity of radiation dose delivery leading to severe hot spots. Tissue compensation is achieved sometimes using square non-divergent aluminum metal pieces in 'Ellis type' compensators. We developed Divergent Wax Tissue Compensator (DWTC) and tested their efficacy in tele-cobalt treatments.

For a photon field of size $20 \times 20 \mathrm{~cm}$ in a telecobalt machine with 'Source Diaphragm Distance (SDD)' of $45 \mathrm{~cm}$, DWTC is designed to provide compensation at 'source skin distance (SSD)' of $80 \mathrm{~cm}$. A jig stand with 3 acrylic perforated sheets kept together at specified gaps allow required radial divergence of the metal spokes on equally spaced grid. Dose compensator could be fabricated by a tray mounted on the top side of the jig, using molten dental wax by measuring patient anatomy created by a positive of 'Plaster of Paris' (POP).

Accuracy of fabricated DWTC is tested using 3-dimensional semi-spherical and wedge shaped contours, and measuring transmitted radiation flux using EDR-2 verification film and evaluation by Vidar scanner. The uniformity of the dose in the treatment region with compensator is well within $3 \%, 3 \mathrm{~mm}$ dose evaluation criteria.

These wax compensators are simple, accurate and they could be adopted in linear accelerator treatments also retaining the dose build up advantage.
\end{abstract}

Key words: Megavoltage radiotherapy; Tissue compensation; Dose uniformity; Head and neck regions

\section{Introduction}

External Beam Radiotherapy (EBRT) remains the mainstay for radical treatments, for malignancies in head and neck regions. Inter-field thickness variations and irregular contour variations are encountered in these patients affecting uniformity in radiation dose delivery. Adverse reactions are encountered because of skewed isodose curves seriously affecting the volume dose variations in treatment planning. This complex situation results in dose inhomogeneity resulting in painful reactions in the head and neck region often discouraging the patient from taking full course of treatment. There are issues relating to adjuvant surgical management when the texture integrity of skin in neck region is not preserved. Nonuniformity of dose in the planned treatment volumes also ad-

() 2015 The Authors. Published by the JScholar under the terms of the Creative Commons Attribution License http://creativecommons.org/licenses/ by $/ 3.0 /$, which permits unrestricted use, provided the original author and source are credited. versely influence normal tissue reactions, affecting effectiveness of the treatment and therefore deter the Quality Of Life (QOL) in the follow up period.

Ever since deep x-ray era, various compensation methods have been reported in literature for such treatments[1-11]. Tissue Compensators (TC) in the shadow tray level of megavoltage beams are implemented to preserve the shape of the isodose curves accounting for tissue beam obliquity, preserve dose build up advantages, and to improve dose delivery. Ellis type compensator[1,2,5] use aluminum ( $\mathrm{Al}$ ) square pellets to construct compensator plates for individual radiotherapy portals. Tissue deficiencies are addressed by fixing small thickness Al rods taking density factor. Commercially available jigs for fabrication of aluminum tissue compensators do not account for beam divergence at the collimator level[12,13]. Effect of tissue compensation has been studied for sites other than head and neck regions and also use of other metals for such work[14-16]. Presence of metal during 
transit of x-ray photons induce low energy scattered x-rays, add recoil electrons increasing surface dose.

In India, around $40 \%$ of head and neck cancers detected are oral malignancies. In addition, there are patients with cancer of nasal cavity, nasopharynx, paranasal sinuses and the oropharynx, where treatment involves the oral cavity as well as neck area[6]. Radiotherapy (with linear accelerators and telecobalt machines) is increasingly being used as an adjunct form of treatment in the management of head and neck cancers. Because of small inter-field separations, there are no specific advantages of linacs over cobalt machines in these treatments. To overcome treatment related morbidity in these treatments, we investigated[17] efficacy of wax tissue compensators accounting for beam divergence, mounted away from the patient on the path of the beam. The dosimetric adequacy in the application of these compensators in clinical situations is highlighted.

\section{Materials and Methods}

\section{Fabrication of jig}

An iso-centric Theratron tele-cobalt machine (Theratronix, Phoenix) with isocentre at $80 \mathrm{cms}$ has been used for delivering head and neck treatments with parallel opposing lateral fields. The shadow tray distance (Source-Diaphragm Distance 'SDD') is $45 \mathrm{cms}$. To simulate radial diverging beam with a field size of $20 \times 20 \mathrm{~cm}$ at isocentre, a special jig was prepared using three perforated Perspex sheets mounted at fixed intervals. Metal spokes pass through all the 3 Perspex sheets through equally distributed holes drilled, in square matrix form. The divergence of pencil beams, with calculated decrement factor at different planes with respect to $80 \mathrm{~cm}$ SSD ensures correct reproducibility in compensator fabrication. This system can estimate contour variations when placed on a 3 dimensional object. Figure 1 and 2 shows the design of the developed jig, the method of taking the impression of semi-spherical and wedge object and the diminished size of fabricated tissue compensator.

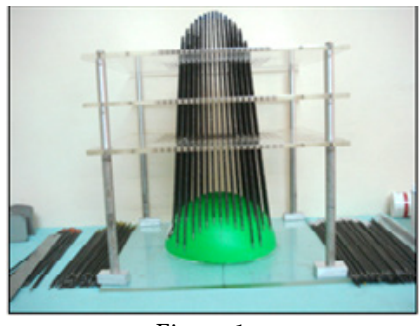

Figure 1

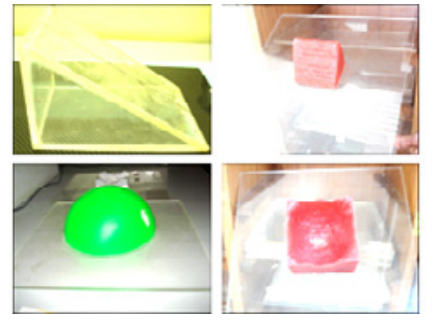

Figure 2
Figure 1: Design of jig for preparation of divergence based wax tissue compensator demonstrated on a semi-spherical phantom object.

Figure 2: Wedge and semi-spherical object and their wax compensator impressions with diminished sizes.

Dental Modeling wax (a tissue equivalent material of density, $\approx 1.00 \mathrm{gm} / \mathrm{cm}^{3}$ ) commercially available in standard sizes $9 \mathrm{x}$ $16 \mathrm{~cm}$ plates, having thickness ranging from $0.2 \mathrm{~cm}$ to 10.0 $\mathrm{cm}$ was used as compensator material. Water equivalence is confirmed by measurements carried out in a water phantom (Model WP30) of size $30 \times 30 \times 30 \mathrm{~cm}$, using $0.6 \mathrm{~cm}^{3}$ ionization chamber connected to an electrometer (CD-SSD-92).

\section{Film dosimetry}

Verification of the obtained water equivalent wax compensa- tor thickness was carried out with Kodak therapy verification film (Extended Dose Range: EDR-2) with and without TC, to confirm improvement in flatness of horizontal radiation beam profiles. (Figure 3 and 4). The films are exposed under these phantoms to a dose of 2 Gy on Phoenix telecobalt unit using SAD technique keeping in a sagittal plane at a depth of 2 $\mathrm{cm}$ with and without TC. Intensity Modulated Radiotherapy Omni Pro film dosimetry software (Wellhoffer Scanditronix, Uppsala, Sweden) was used to evaluate film response with VXR-16 vidar scanner. Flatness, symmetry, uniformity in radiation intensity were checked with the available software.

\section{Clinical use of DWTC}

For patients planned for bilateral curative radiotherapy for head and neck tumors were taken for tissue compensation. These patients were immobilized with appropriate mould sheets. A positive Plaster of Paris (POP) mould is prepared for the head and neck together, in the mould room. This was kept under the jig and the metal spokes were run to obtain the shape at the tray level accounting for beam divergence. Diminished size wax impression mould is obtained incorporating the 'decrement factor $45 \mathrm{~cm} / 80 \mathrm{~cm}=0.563$. Separate divergent TCs were prepared for left and right sides of treatments. The fabricated TCs were fixed on a Perspex tray maintaining correct positioning with respect to central axis of radiation treatment portal. The two compensators showing their orientations and treatment execution in the presence of compensator in shadow tray of cobalt machine is seen Figure 5 and 6.

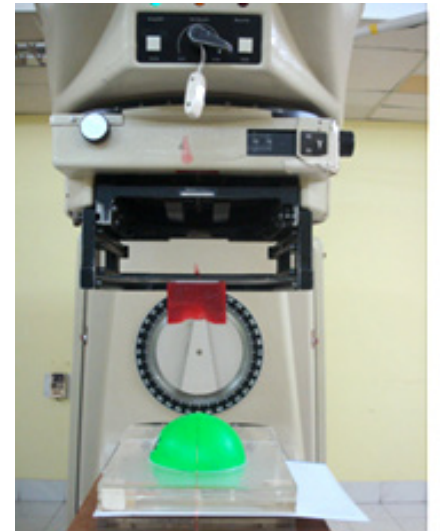

Figure 3

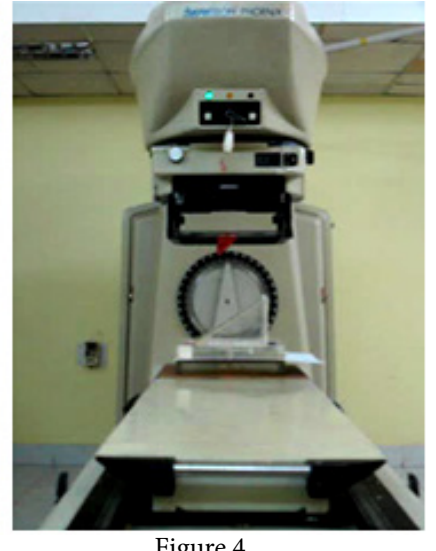

Figure 4
Figure 3: Geometry of taking fluence pattern on the EDR-2 film for the semipherical object at SSD and corresponding compensator in the tray level. Figure 4: Geometry of taking fluence pattern on the EDR-2 film for the Perspex wedge object at SSD and corresponding compensator in the tray level.

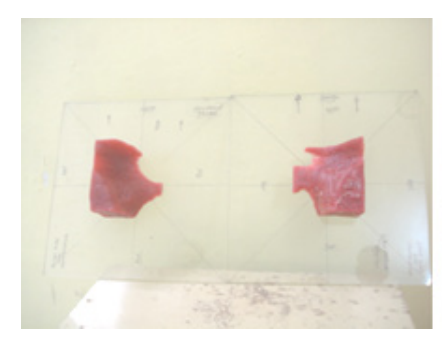

Figure 5

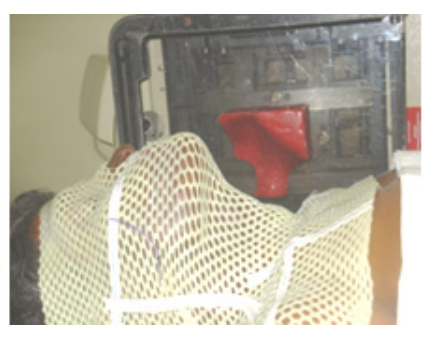

Figure 6
Figure 5: Wax based divergent compensators made for left and right halves of the neck portion of a patient

Figure 6: Wax compensator of the left lateral field fixed on the shadow tray along with patient in treatment position. 


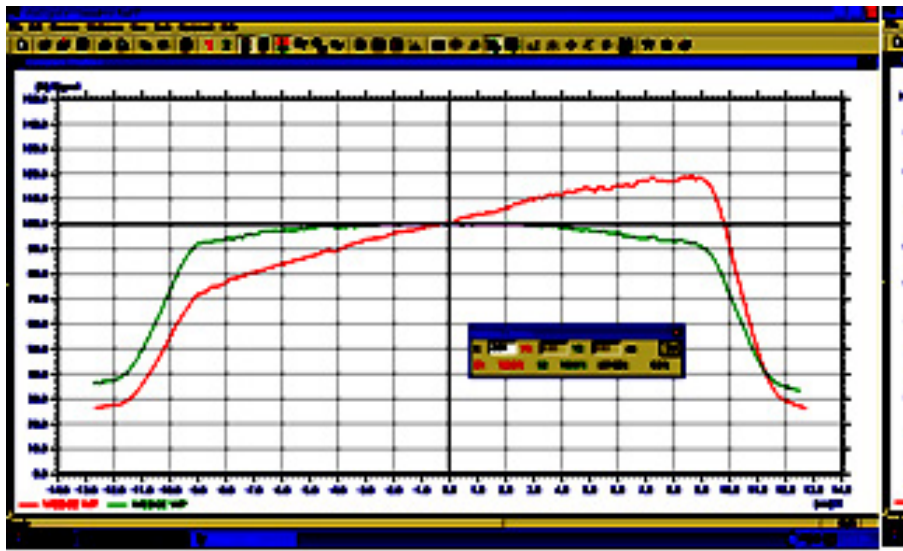

Figure 7

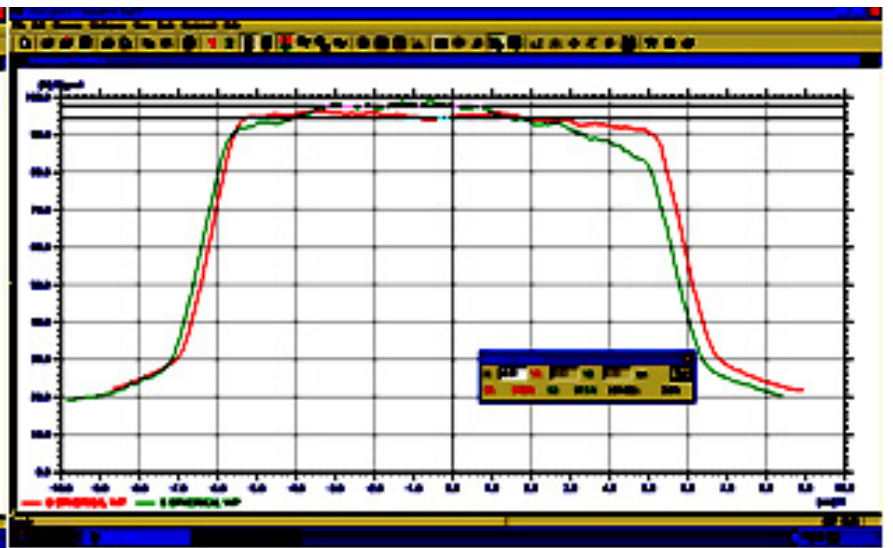

Figure 8

Figure 7: EDR-2 measured intensity profiles with and without compensator for wedge shaped Perspex phantom Figure 8: EDR-2 measured intensity profiles with and without compensator for semi-spherical object
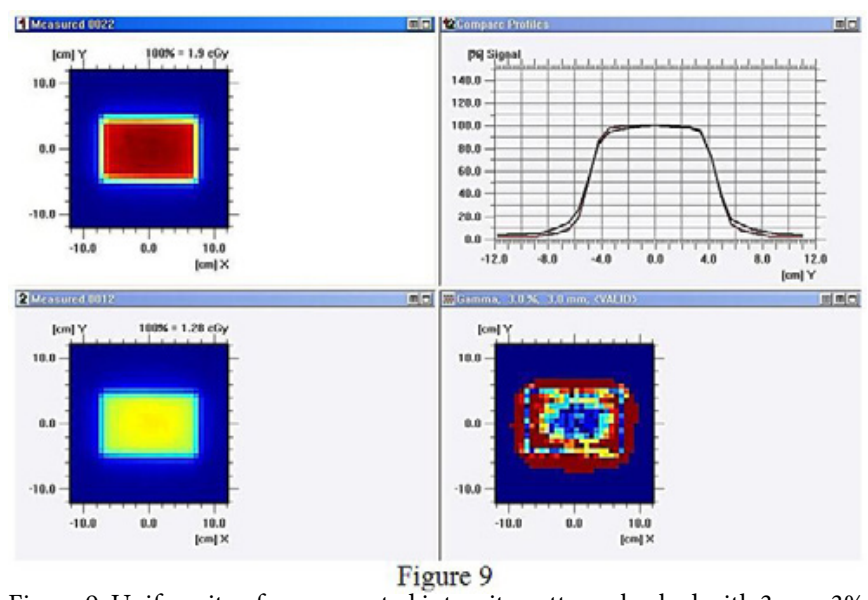

Figure 9: Uniformity of compensated intensity pattern checked with $3 \mathrm{~mm}, 3 \%$ dose evaluation criterion.

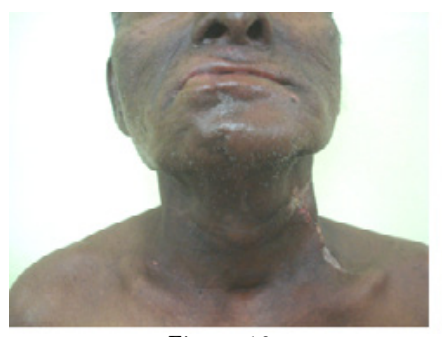

Figure 10

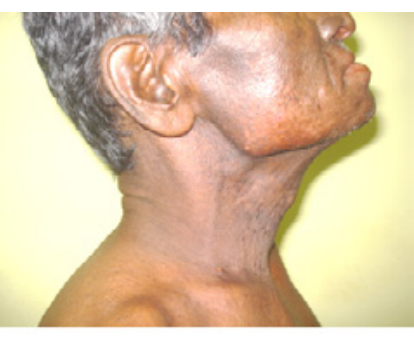

Figure 11
Figure 10: Uniformity of patient's skin reaction during treatment (seen in Antero-Posterior view) treated with presence of tissue compensator during treatment.

Figure 11: Uniformity of patient's skin reaction during treatment (seen in Right Lateral view)

\section{Results}

Water phantom measurements of beam transmission gave broad beam attenuation coefficients for water and wax showing good equivalence within $2-3 \%\left(\mu_{\text {water }}=0.048 \mathrm{~cm}^{-1}\right.$ and $\left.\mu_{\text {dental wax }} 0.049 \mathrm{~cm}^{-1}\right)$ Flatness of horizontal profiles as obtained with TC is found to be within $\pm 1 \%$ without any spikes showing homogeneity in the fabricated wax impressions. The wedge and semi-spherical wax impressions gave the required shapes (Figure 7 and 8 ) as confirmed from the profile plots with the scanner. The uniformity of the dose in the region with compensation is well within $3 \%, 3 \mathrm{~mm}$ dose evaluation criteria (Figure 9).

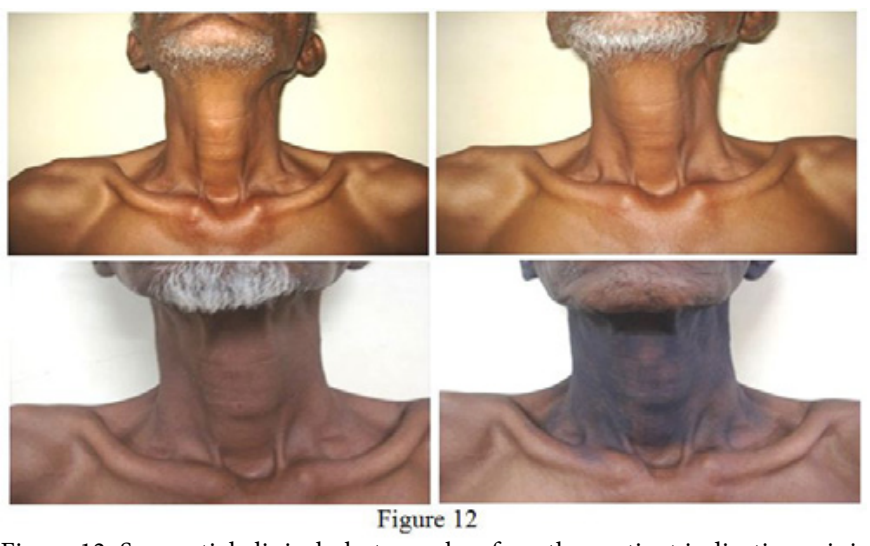

Figure 12: Sequential clinical photographs of another patient indicating minimum radiation sequalae at completion of treatment and in the follow up period.

In Figure 10 and 11 the AP and Lateral views of the irradiated patient, shows the uniformity in radiation reaction indicating the efficacy of designed DWTC for clinical applications. Figure 12 illustrates sequential clinical photographs of a treated patient indicating minimum radiation sequelae at the end of treatment and in the follow up period.

\section{Discussion}

This study has systematically presented the clinical implementation of a wax-compensator based radiotherapy treatments at our center. It is brought out clearly that any shape of the contour could be corrected for tissue obliquity. For the quality assurance aspect we have shown regular objects like wedges and semispherical shapes checked with water phantom and film dosimetry. These wax based divergent tissue compensator is superior in reducing hot spots to improve overall dose homogeneity, without introducing additional corpuscular stray radiations like metal filters. The safety of their applications and optimal dose delivery were well demonstrated.

Enormous irregularities in patient geometry in the superiorinferior planes lead to hot and cold spots, giving complex dosimetric situations. Beam modulation methods like IMRT either adds or blocks radiation intensity with increase in monitor units and also bringing in un-necessary beam orientations to obtain optimization. The presence of wax compensator in the 
path of the beam corrects for absence of tissue, and brings in dose delivery to 'near perfect' situation reducing additional uncertainties. 2-D compensators fabricated by milling machines use computerized tomography CT images through DICOM transfer depends on electronic technology adding to cost of treatment, in addition making introduction of metal filters which may give rise to stray radiations, thereby increasing the risks of second malignancies in peripheral zones. In Figure 8 it appears that it is difficult to say that semi-spherical wax impressions give the required shapes. This is because, though the semi spherical wax impression did not give the required shape as clearly as that for the wedge phantom, this is due to the fact that the profile was taken along a small area on the top of the semi-sphere around the central axis of the phantom. Figure 8 exhibited more of a method to check a fabricated compensator with an external dosimetry system if required. Regarding phantom selection we have resorted to closely mimic the clinical situations in the head and neck regions. Neck is usually semi cylinder in shape with variations along the medial to lateral borders. A semi spherical hollow object (a plastic ball of diameter $16 \mathrm{~cm}$ cut in half and closed along the base of the hemi sphere by Perspex sheet) filled with water is selected for dosimetry. A perspex sheet is used in order to verify the fluence pattern under 'IMatrix' with and without the compensator. A semi cylindrical shape of the neck has only 2 dimensional contour variation. However a semi spherical water phantom will have much higher degree of contour variation (3 dimensional). Hence a semi spherical water phantom was selected for dosimetric purposes to validate the uniformity of the fluence with the compensator. It is clarified that this wax compensator can address irregular shapes of outer contour but will not account for inhomogeneities inside the neck in terms of air space and cartilage.

Employing this cost effective type of tissue compensators, the dose inhomogeneity can be reduced to within $5 \%$ which has significant applications in the developing world. Good homogenous agreement is observed with film dosimetry thus instilling confidence in more optimal treatment delivery. The dosimetric custom compensation method is highly accurate, and reproducible. In a simple mould room setup, the custom made divergent wax based tissue compensator could be fabricated with insignificant cost, without much of sophisticated inputs. Our study with cobalt beams could also be extended in linacs because the divergence of the beam is less with more SSD with respect to tray level. Also tissue equivalence could be confirmed with the beam quality before implementation. Beam hardening effects also will be minimal with wax material. This technique will allow the radiation oncologists to treat patients with head and neck radiation fields in a most efficient manner. This concept could be generalized for tissue obliquities in the scalp and breast regions and suitable compensation could be achieved with careful prostheses.

\section{Acknowledgements}

We thank the Dean, Kasturba Medical College Hospital, Mangalore for the kind permission to pursue this scientific work. Technical help from radiation technologists Mr.Balakrishna, Mr.Harish Rao, Mr.Shine K, Mr. Akhil Kumar is gratefully acknowledged.

JScholar Publishers

\section{References}

1) Ellis F, Hall E J, Oliver R (1959) A compensator for variations in tissue thickness for high energy beams. Br J Radiol 32:421-422.

2) Hall EJ, Oliver R (1961) The use of standard isodose distribution with high energy radiation beams - The accuracy of a compensator technique in correcting for body contours. Br J Radiol 34: 43-52.

3) Lueng PMK, Van DJ, Robins J ( 1974) A method for large irregular field compensation. Br J Radiol 47: 805- 810.

4) Khan FM, Jeffrey FW, Wilfred S, Tale HK (1980) Basic data for dose calculation and compensation. Int J Radiat Oncol Biol Phys 6: 745751.

5) Khan FM (1984) The Physics of Radiation Therapy. 1st ed. Baltimore: Williams and Wilkins.

6) Henderson SD, Purdy JA, Gerber, RL et al. (1987) Dosimetry considerations for a Lipowitz metal tissue compensator system. Int J Radiat Oncol Biol Phys 13:1107-1112.

7) Clark BG, Evans MDC (1988) Standard compensators for ENT therapy fields. Med Dosim 13: 173-177.

8) Coia L, Galvin J, Sontag M, Blitzer P, Brenner H, et al. (1991) Three-dimensional photon treatment planning in carcinoma of the larynx. Int J Radiat Oncol Biol Phys 21: 183-192.

9) Ansbacher W, Robinson DM, Scrimger JW (1992) Missing tissue compensators: Evaluation and optimization of a commercial system. Med Phys 19:1267-1272.

10) Ayyangar KM, Mohiuddin M. (1996) Differential dose delivery for cancers of the head and neck. Med Dosim 21:1-5.

11) Harari PM, Sharda NN, Brock LK, Paliwal BR (1998) Improving dose homogeneity in routine head and neck radiotherapy with custom 3-D compensation. Radiat Oncol 49: 67-71.

12) Dasa Grabec, Primoz Strojan (2005) Missing tissue compensation with wax filter compensators in radiotherapy of the head and neck region. Radiol Oncol 39: 219-224.

13) DayanandaS, Malhotra HK, Agarwal JP, Nehru RM, Sankar A, et al. (2001) Dosimetric characteristics of aluminum tissue compensator for 60Co and 6 MV X-rays. J Med Phys 26:23-28.

14) Krishna PM, Donald HB, Pranab R. (1980) Thin lead sheets as tissue compensators for larger field irradiation. Int J Radiat Oncol Biol Phy 6: 513-517.

15) Leibel SA, Kutcher GJ, Harrison LB, Fass DE, Burman CM, et al. (1991) Improved dose distributions for 3D conformal boost treatments in carcinoma of the nasopharynx. Int J Radiat Oncol Biol Phys 20:823-833.

16) LoSasso T, Chui CS, Kutcher GJ, Leibel SA, Fuks Z, et al. (1993) The use of a Multileaf collimator for conformal radiotherapy of carcinomas of the prostate and nasopharynx. Int J Radiat Oncol Biol Phys 25: 61-70.

17) C Srinivas, K Shenoy, V Shenoy, B Kulal, R Ravichandran, et al. (2011) Fabrication of Divergent Wax based compensators for Head and Neck Radiotherapy. Abstract. COMP Conference Proceedings. Med Phys 38:3394. 
Submit your manuscript to a JScholar journal and benefit from:

ब Convenient online submission

- Rigorous peer review

- Immediate publication on acceptance

- Open access: articles freely available online

9 High visibility within the field

9 Better discount for your subsequent articles

Submit your manuscript at http://www.jscholaronline.org/submit-manuscript.php 